\title{
Displacement of Surgical Clips in Patients with Human Acellular Dermal Matrix in the Excision Cavity during Whole Breast Irradiation Following Breast-Conserving Surgery
}

\author{
Wonguen Jung, MD, $P h D^{1}$ \\ Kyubo Kim, MD, PhD' \\ Nam Sun Paik, MD, PhD²
}

Departments of ${ }^{1}$ Radiation Oncology and ${ }^{2}$ Surgery, Ewha Womans University College of Medicine, Seoul, Korea
Correspondence: Kyubo Kim, MD, PhD Department of Radiation Oncology, Ewha Womans University College of Medicine, 1071 Anyangcheon-ro, Yangcheon-gu, Seoul 07985, Korea

Tel: 82-2-2650-5334

Fax: 82-2-2654-0363

E-mail: kyubokim.ro@gmail.com

Received April 18, 2019

Accepted August 12, 2019

Published Online August 13, 2019

\section{Purpose}

The purpose of this study was to investigate the displacement of surgical clips in the excision cavity during whole breast irradiation following breast-conserving surgery (BCS) with or without acellular dermal matrix (ADM) insertion, and to analyze clinicopathologic factors associated with the displacement of surgical clips.

\section{Materials and Methods}

From 2016 to 2017, 100 consecutive breast cancer patients who underwent BCS with the placement of surgical clips (superior, inferior, medial, lateral, and deep sides) in the tumor bed were included in this study. All patients took first planning computed tomography (CT) scan (CT 1) before whole breast irradiation and second CT scan (CT 2) before boost irradiation. Between two sets of planning $\mathrm{CT}$, the displacement of surgical clips was calculated from the $\Delta \mathrm{X}$ (lateral-medial), $\Delta \mathrm{Y}$ (anterior-posterior), $\Delta \mathrm{Z}$ (superior-inferior), and threedimensional (3D) directions. Patients were divided into two groups according to the breast volume replacement with $A D M$ : group $A$ with $A D M$ and group $B$ without $A D M$.

\section{Results}

The means and 1 standard deviations of 3D displacement for superior, inferior, medial, lateral and deep clips were 5.2 $\pm 2.9,5.2 \pm 3.2,5.6 \pm 4.5,5.6 \pm 4.3$, and $4.9 \pm 4.9 \mathrm{~mm}$ in entire cohort $(n=100) ; 5.6 \pm 2.6,6.0 \pm 3.5,6.7 \pm 5.8,6.7 \pm 5.7$, and $6.1 \pm 7.4 \mathrm{~mm}$ in group $A(n=38)$; $4.9 \pm 3.1,4.8 \pm 3.0,5.0 \pm 3.5,5.0 \pm 2.9$, and $4.3 \pm 2.8 \mathrm{~mm}$ in group $B(n=62)$, respectively. The $3 \mathrm{D}$ displacements of group $A$ were longer than those of group $B$, but only significant difference was observed in lateral clip $(p=0.047)$.

\section{Conclusion}

This study demonstrated displacement of surgical clips during whole breast irradiation in patients with ADM insertion. For patients who had breast volume replacement using ADM, adaptive boost planning should be considered.

\section{Introduction}

Whole breast irradiation following breast-conserving surgery $(\mathrm{BCS})$ is a standard treatment for patients with earlystage breast cancer. Boost radiotherapy (RT) is usually delivered to the excision cavity, because randomized trials have shown that local recurrences are significantly reduced by dose escalation to the tumor bed $[1,2]$. The tumor bed is iden-
Key words

Breast-conserving surgery, Surgical clip, Displacement, Radiotherapy, Acellular dermal matrix 
indeterminate margins proved to be independent risk factors for local recurrence and it is important to achieve a clear margin with wide excision [13-15]. However, the larger excision volume of breast tissue removed during BCS, the poorer cosmetic outcome [16]. In our institution, acellular dermal matrix (ADM) is used for breast volume replacement to fill large defects in the excision cavity, but the impact of ADM insertion on the displacement of surgical clips has not been reported yet.

The purpose of this study was to evaluate the displacement of surgical clips which could influence boost field, and to identify risk factors associated with this change during whole breast irradiation following BCS with or without ADM insertion.

\section{Materials and Methods}

\section{Patients}

From January 2016 to December 2017, 100 consecutive breast cancer patients who underwent BCS with the placement of surgical clips in the tumor bed and received adjuvant RT were included in the current study. Surgeons usually marked the tumor bed with five surgical clips, which were placed at the superior, inferior, medial, lateral, and deep sides. When the volume of excised breast tissue was large, ADM was inserted in the excision cavity at the discretion of attending surgeon. The ADM used in this study was a crosslinked human ADM, MegaDerm (L\&C BIO, Seongnam, Korea). Patients were divided into two groups according to the breast volume replacement with ADM; group A was defined as patients with ADM, and group B as those without ADM. The records including the clinical characteristics, radiological findings, operation findings, pathology reports, planning computed tomography (CT) images, and any other clinical correspondence were reviewed retrospectively. A positive surgical margin was defined as having tumor (ductal carcinoma in situ or invasive) seen at the inked edge of the specimen, a close surgical margin as tumor seen within $1 \mathrm{~mm}$ of the inked cut edge, and a negative surgical margin as tumor more than $1 \mathrm{~mm}$ from the inked cut edge.

\section{CT simulation scan and radiotherapy planning}

All patients took an initial planning CT scan (CT 1) before whole breast irradiation and a second planning CT scan (CT 2) before boost irradiation. Two hundred CT scans were analyzed for the 100 patients. The planning CT was scanned in the supine position with elevated both arms above the head, on GE Discovery CT 590 RT Simulator (GE Healthcare, Waukesha, WI). The position was immobilized using a breast board. The superior margin of the whole breast was the level of sternal notch, the inferior margin was $2 \mathrm{~cm}$ below the inframammary fold, the medial margin was the midline, and the lateral margin was the midaxillary line. The interslice thickness of the CT scans was $5.0 \mathrm{~mm}$. All CT scans were obtained from the level of the mandible to the lung bases. Both CT 1 and CT 2 image sets were sent to MIM software ver. 6.7 (Cleveland, $\mathrm{OH}$ ) for contouring and then imported to treatment-planning software system Eclipse ver. 10.0 (Varian Medical Systems, Palo Alto, CA). A dose of 50.4 Gy in 28 fractions to the whole breast and a boost dose of 9 to $15 \mathrm{~Gy}$ to the tumor bed was delivered. The same physician (W.J.) performed all of the contouring procedures for consistency. The structures of sternal notch, each individual surgical clip, ADM, and seroma were manually delineated on both CT images. The ADM was distinct from breast parenchyma on the planning CT (Fig. 1).

\section{Evaluation of displacement of surgical clips}

The reference point for evaluating displacement of surgical clips was placed at the center of the sternal notch. The cen-
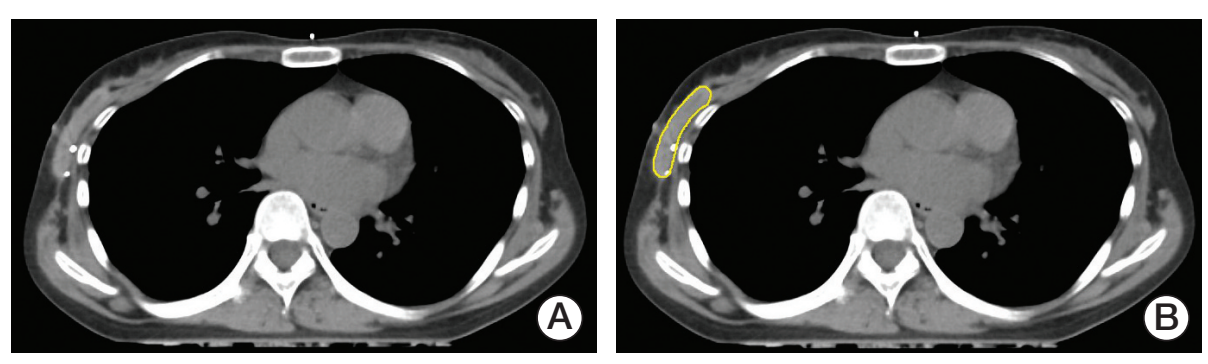

Fig. 1. Delineation of acellular dermal matrix (ADM) (yellow) on initial planning computed tomography (CT). (A) Native CT image. (B) Corresponding CT image with delineation of ADM. 
troid coordinates of each structure (sternal notch and each clip) on both CT scans were computed using the MIM software including $X$ (lateral-medial), Y (anterior-posterior), and $Z$ (superior-inferior). The relative coordinates of surgical clips from the reference point on both CT scans were then calculated manually. The displacement of $\Delta \mathrm{X}, \Delta \mathrm{Y}$, and $\Delta \mathrm{Z}$ between CT 1 and CT 2 for each surgical clip was calculated by subtracting the CT 1 coordinates from the CT 2 coordinates according to the following equation: (coordinates of each clip of CT 1)-(coordinates of each clip of CT 2). The coordinates on both $\mathrm{CT}$ scans were compared to measure the displacement of surgical clips in a three-dimensional (3D) direction. The 3D distance of displacement was calculated by the formula: $\sqrt{\left(\Delta X^{2}+\Delta Y^{2}+\Delta Z^{2}\right)}$.

\section{Statistical analyses}

The normality of data distribution was tested using the Kolmogorov Smirnov test. The means and standard deviations (SDs) of displacement of surgical clips and volumetric change of seroma and ADM were calculated for each patient. Independent $t$ test, Mann-Whitney and linear regression analysis test were used to evaluate possible associations between displacement of surgical clips and clinicopathologic factors including body mass index, pathologic tumor size, interval between BCS and the start of RT, volume of tissue removed, volumetric change of ADM, laterality, tumor location, axillary surgery, RT field, the use of ADM, and the presence of seroma. The displacement of surgical clips were compared between group A and group B using the independent $t$ tests and Mann-Whitney tests as appropriate. All $\mathrm{p}$-values were two-sided, and $\mathrm{p}<0.05$ was considered as statistically significant. Statistical analyses were done using SPSS software ver. 18.0 (SPSS Inc., Chicago, IL).

\section{Ethical statement}

The institutional review board approved this study (No. 2017-10-044 at Ewha Womans University Mokdong Hospital) and waived the requirement for obtaining informed consent.

\section{Results}

The patient and tumor characteristics are summarized in Table 1. The median age at diagnosis was 49 years (range, 28 to 74 years). The median interval from surgery to the start of RT was 8.3 weeks (range, 3.9 to 36.1 weeks), and the median interval between the initiation of RT and boost irradiation
Table 1. Patient and tumor characteristics

\begin{tabular}{|c|c|}
\hline Variable & $\begin{array}{l}\text { No. of patients } \\
(n=100)\end{array}$ \\
\hline Age (yr) & $49(28-74)$ \\
\hline BMI $\left(\mathrm{kg} / \mathrm{m}^{2}\right)$ & $22.9(17.5-37.1)$ \\
\hline Pathologic tumor size $(\mathrm{cm})$ & $1.6(0-6.0)$ \\
\hline $\begin{array}{l}\text { Interval between surgery and } \\
\text { start of RT (wk) }\end{array}$ & $8.3(3.9-36.1)$ \\
\hline Volume of tissue removed $(\mathrm{mL})$ & $100.8(3.3-645.2)$ \\
\hline \multicolumn{2}{|l|}{ Laterality } \\
\hline Right & 57 \\
\hline Left & 43 \\
\hline \multicolumn{2}{|l|}{ Tumor location (quadrant) } \\
\hline Upper-outer & 39 \\
\hline Upper-inner & 29 \\
\hline Lower-outer & 18 \\
\hline Lower-inner & 14 \\
\hline \multicolumn{2}{|l|}{ Axillary surgery } \\
\hline No/SLNB & 81 \\
\hline ALND & 19 \\
\hline \multicolumn{2}{|l|}{ (y)pT stage } \\
\hline 0 or is & 7 \\
\hline 1 & 56 \\
\hline 2 & 36 \\
\hline 3 & 1 \\
\hline \multicolumn{2}{|l|}{ No. of involved axillary LNs } \\
\hline 0 & 70 \\
\hline $1-3$ & 23 \\
\hline $4-9$ & 6 \\
\hline$\geq 10$ & 1 \\
\hline \multicolumn{2}{|l|}{ Resection margin } \\
\hline Negative & 79 \\
\hline Close & 13 \\
\hline Positive & 8 \\
\hline \multicolumn{2}{|c|}{ Breast volume replacement using ADM } \\
\hline Yes & 38 \\
\hline No & 62 \\
\hline \multicolumn{2}{|l|}{ Chemotherapy } \\
\hline Yes & 63 \\
\hline No & 37 \\
\hline \multicolumn{2}{|l|}{ RT field } \\
\hline WBI & 74 \\
\hline WBI+RNI & 26 \\
\hline
\end{tabular}

Values are presented as median (range) or number. BMI, body mass index; RT, radiotherapy; SLNB, sentinel lymph node biopsy; ALND, axillary lymph node dissection; LN, lymph node; ADM, acellular dermal matrix; WBI, whole breast irradiation; RNI, regional nodal irradiation. 

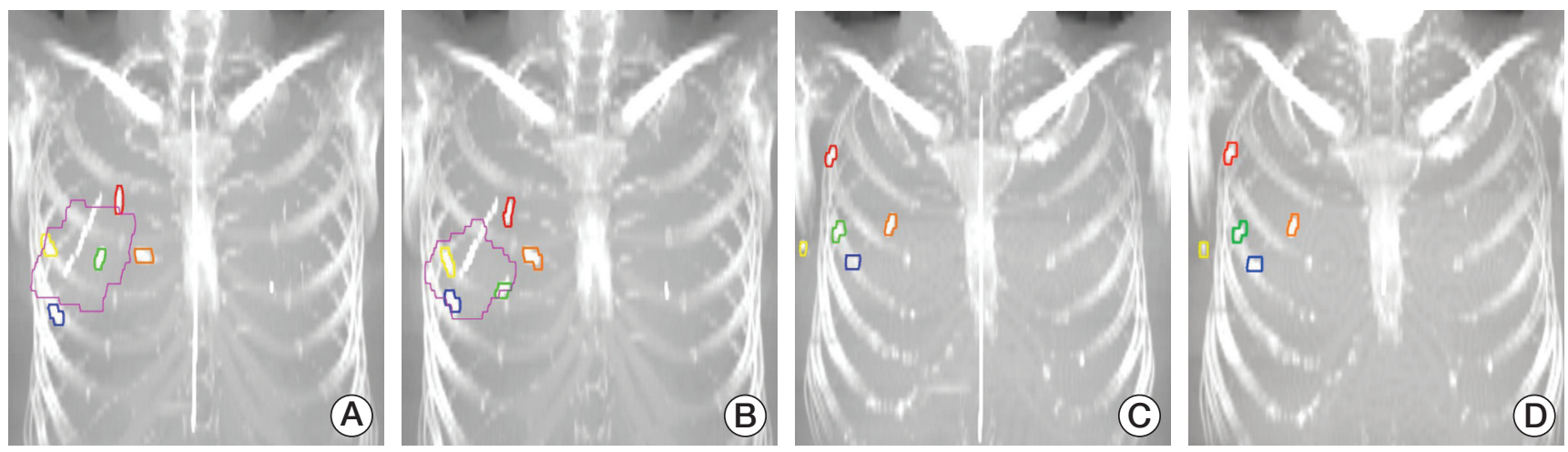

Fig. 2. The displacement of surgical clips (superior clip-red, inferior clip-blue, medial clip-orange, lateral clip-yellow, and deep clip-green) in a right breast cancer patient before whole breast irradiation $(A, C)$ and before boost irradiation (B, D). (A, B) In a patient with acellular dermal matrix (ADM) (margenta), the three-dimensional (3D) displacement for superior, inferior, medial, lateral, and deep clips were $11.4 \mathrm{~mm}, 16.2 \mathrm{~mm}, 5.1 \mathrm{~mm}, 9.6 \mathrm{~mm}$, and $25.3 \mathrm{~mm}$, respectively. (C, D) In a patient without ADM, the 3D displacement for superior, inferior, medial, lateral, and deep clips were $1.4 \mathrm{~mm}, 2.3 \mathrm{~mm}, 2.3$ $\mathrm{mm}, 2.7 \mathrm{~mm}$, and $1.4 \mathrm{~mm}$, respectively.

was 5 weeks (range, 4.6 to 6.0 weeks) in the entire cohort. Neoadjuvant chemotherapy was performed in 12 patients $(12.0 \%)$, and concurrent or adjuvant chemotherapy was performed in 51 patients $(51.0 \%)$. For patients with neoadjuvant or concurrent chemotherapy or without chemotherapy, the median period from surgery to the start of RT was 6.4 weeks (range, 3.9 to 9.6 weeks). For patients with adjuvant chemotherapy, the median period from surgery to the start of RT was 28.3 weeks (range, 15.6 to 36.1 weeks).

Group A consisted of 38 patients with breast volume replacement using ADM, and group B consisted of 62 patients without ADM. The mean volume of ADM was $44.51 \mathrm{~cm}^{3}$ on CT 1 and $40.58 \mathrm{~cm}^{3}$ on CT 2, respectively. The mean volumetric change in $\mathrm{ADM}$ was $-8.2 \%(\mathrm{p}<0.001)$. The volume of $\mathrm{ADM}$ decreased in 32 of 38 patients $(84.2 \%)$ during whole breast irradiation. Forty patients $(40 \%)$ had seroma on CT 1 and CT 2 (25/38 patients in group A; $15 / 62$ patients in group $B)$. The presence of seroma on CT 1 was significantly correlated with the presence of ADM $(p<0.001)$. The mean seroma volume on CT 1 and CT 2 were significantly different at $10.14 \mathrm{~cm}^{3}$ and $6.61 \mathrm{~cm}^{3}$, respectively $(\mathrm{p}<0.001)$. The volume of seroma decreased in 34 of 40 patients $(85.0 \%$ ) during whole breast irradiation. The mean reduction in seroma volume between CT 1 and CT 2 was $47.4 \%$.

The means and $1 \mathrm{SD}$ of the 3D displacement for superior, inferior, medial, lateral, and deep clips were 5.2 $\pm 2.9,5.2 \pm 3.2$, $5.6 \pm 4.5,5.6 \pm 4.3$, and $4.9 \pm 4.9 \mathrm{~mm}$, respectively, in all patients. Association between clinicopathologic factors and displacement of surgical clips was shown in Table 2. According to the use of $\mathrm{ADM}$, the means and $1 \mathrm{SD}$ of the $3 \mathrm{D}$ displacement for superior, inferior, medial, lateral and deep clips were
$5.6 \pm 2.6,6.0 \pm 3.5,6.7 \pm 5.8,6.7 \pm 5.7$, and $6.1 \pm 7.4 \mathrm{~mm}$ in group A; $4.9 \pm 3.1,4.8 \pm 3.0,5.0 \pm 3.5,5.0 \pm 2.9$, and $4.3 \pm 2.8 \mathrm{~mm}$ in group B, respectively (Table 3 ). The 3D displacements of surgical clips in group A were longer than those in group B, but only significant difference was observed in the lateral clip ( $p=0.047$ ) (Fig. 2). In group A, the volumetric change of ADM was significantly proportional to the $3 \mathrm{D}$ displacement in inferior clip $(\mathrm{R}=0.343, \mathrm{p}=0.037)$.

According to the presence of seroma, the means and $1 \mathrm{SD}$ of the 3D displacement for superior, inferior, medial, lateral and deep clips were $5.8 \pm 2.4,6.0 \pm 3.4,6.7 \pm 5.7,6.3 \pm 4.8$, and $5.7 \pm 6.7$ in patients with seroma; $4.8 \pm 3.2,4.7 \pm 3.1,4.9 \pm 3.4$, $5.2 \pm 3.8$, and $4.4 \pm 3.1$ in patients without seroma, respectively. The 3D displacements in patients with seroma were longer than those in patients without seroma, but only significant difference was observed in inferior clip ( $p=0.045)$.

According to the interval from surgery to the start of RT, divided by the median 8 weeks, the means and 1 SD of the 3D displacement for superior, inferior, medial, lateral, and deep clips were $5.4 \pm 2.9,5.6 \pm 3.6,6.9 \pm 5.5,5.6 \pm 4.6$, and $5.6 \pm 6.3$ $\mathrm{mm}$ in patients starting RT within 8 weeks; $5.0 \pm 3.0,4.9 \pm 2.9$, $4.6 \pm 3.2,5.6 \pm 4.0$, and $4.3 \pm 3.0 \mathrm{~mm}$ in patients starting RT after 8 weeks, respectively (Table 4 ). The 3D displacements in patients starting RT within 8 weeks after BCS were longer than those in patients starting RT after 8 weeks, but only significant difference was observed in the medial clip ( $\mathrm{p}=0.009)$. 


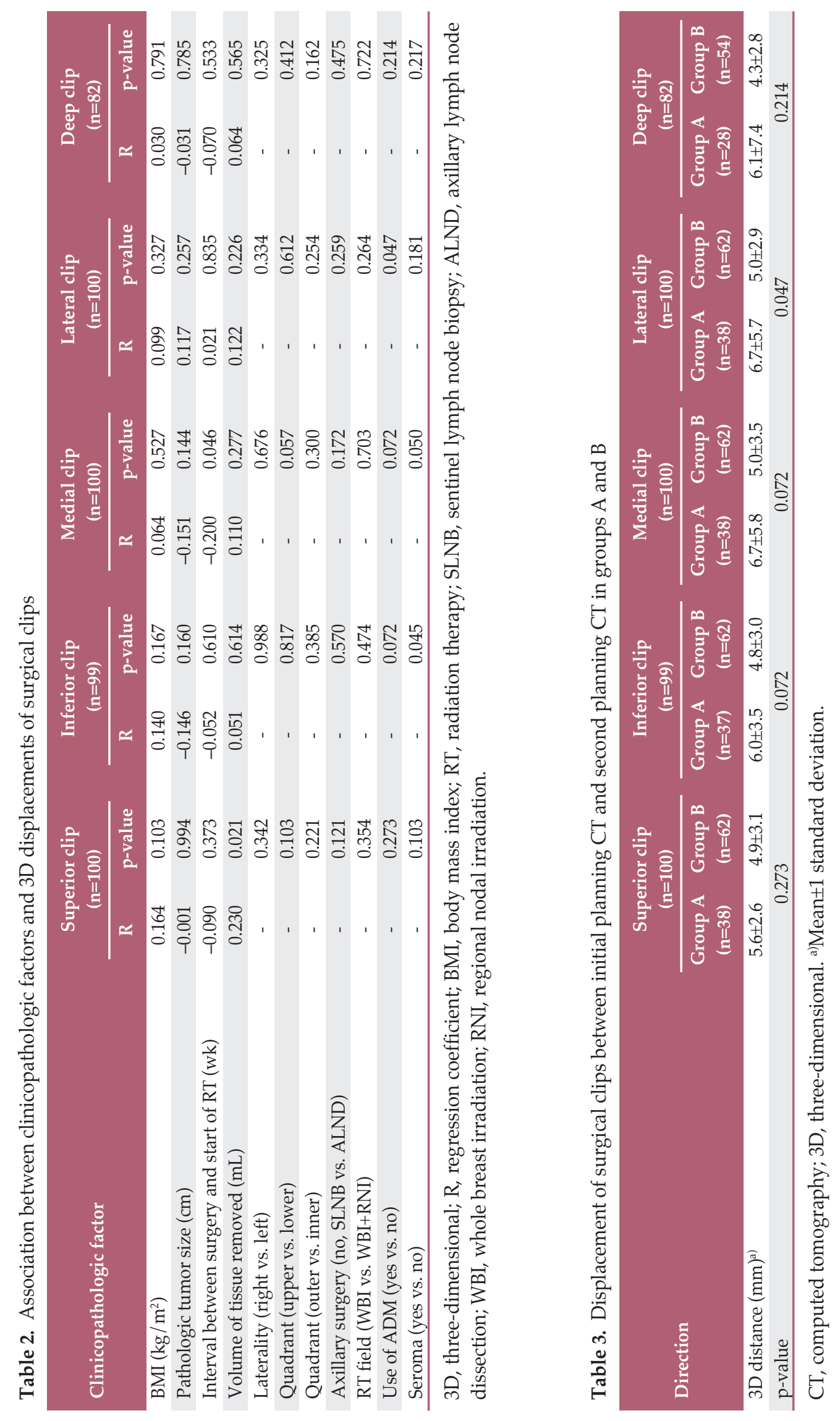




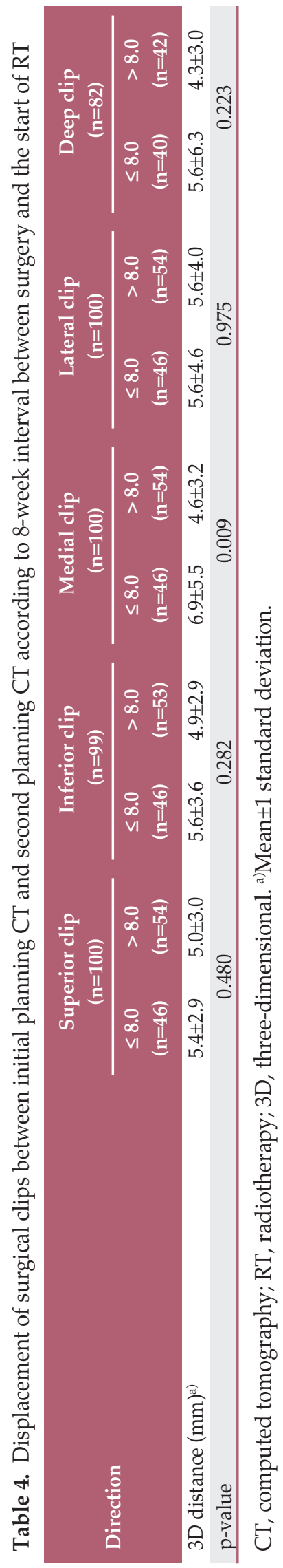

\section{Discussion}

The current study showed that the displacement of surgical clips in the excision cavity occurred during whole breast irradiation. Displacement of surgical clips was longer as the interval from surgery to initiation of RT was shorter and $\mathrm{ADM}$ was present in the excision cavity.

The excision cavity is the main target of boost RT because local recurrence usually occurs in the tumor bed after BCS. Better delineation of the tumor bed optimizes coverage of the target volume and minimizes the volume of irradiated normal breast tissue, and also improves both local control and cosmetic outcome. The tumor bed for boost RT is usually delineated using the surgical clips or surgical scar, postoperative change, seroma and/or hematoma. Among these, surgical clips in the excision cavity are helpful in defining the depth of excision cavity and the shape of boost field. Some previous reports demonstrated that surgical clips placed in the excision cavity can increase the accuracy to define the boost field [6-8,17]. Bedwinek [6] reported that when boost plans were defined by the surgical scar, 19 of 35 cases (54\%) had the surgical clips outside the boost field. Denham et al. [17] compared the adequacy of clinically derived plans from surgical scar, surgical notes, and primary tumor location to those demarcated by surgical clips; in their study, 10 of 24 $(42 \%)$ of clinically derived boost plans provided inadequate coverage of the tumor bed as defined by surgical clips.

To determine accurate tumor bed with surgical clips, the displacement of surgical clips during whole breast irradiation is an important consideration. In our study, an average $3 \mathrm{D}$ displacement of $5 \mathrm{~mm}$ was seen in each surgical clip during whole breast irradiation. The displacement of surgical clips was also reported by other studies [9-12]. Sung et al. [9] showed the results of displacement of surgical clips on CT before whole breast RT and boost RT. In their study, the median displacement of 3D distance was $5.3 \mathrm{~mm}$, which was similar to our study. The possible explanation for displacement of surgical clips is that the change of tumor bed during whole breast irradiation. In the previous studies, a volume reduction of the tumor bed was reported to be 5\%-44.6\% $[12,18,19]$. Whole breast RT takes approximately 5 to 6 weeks with the conventional fractionation. Volume and shape of the tumor bed may change during the treatment because contraction, fibrosis, and fluid absorption may continue. Therefore, displacement of the surgical clips inserted in the excision cavity may occur due to changes of the tumor bed.

Volume replacement at the time of BCS with the use of musculosubcutaneous flaps for reconstruction of defects after quadrantectomy resection allows extensive resection with a good cosmetic result [20]. At our institution, breast volume replacement with $\mathrm{ADM}$ in the tumor bed was app- 
lied to patients treated by BCS to improve cosmesis. In our analysis, patients with ADM showed longer displacement of surgical clips than those without ADM in the tumor bed. In a previous study, Alco et al. [21] noted that in patients who underwent oncoplastic BCS using latissimus dorsi miniflaps, the tumor bed markedly shifted from the primary location in eight of 22 patients $(36.4 \%)$, and the shift of geometric isocenter coordinates between before and after surgery was measured over $1 \mathrm{~cm}$ in all directions and up to 5.67 $\mathrm{cm}$ in the y directions. In their study, they also reported that the electron field for tumor bed boost did not encompass the location of gross tumor volume before surgery in six of 22 $(27.3 \%)$ patients, leading to underdosage in this region. Given these observation, the breast volume replacement using ADM, like the latissimus dorsi mini-flap in the excision cavity may also affect the displacement of the surgical clip within the tumor bed.

The current data showed that the presence of seroma was significantly associated with 3D displacement of inferior clip. In particular, the formation of seroma is more prevalent in patients with ADM. A previous study reported that larger seroma volume in the surgical bed is a risk factor associated with the displacement of the surgical clip [9]. A systematic review by Jordan et al. [22] suggested that ADM may lead to inflammation as a foreign body response to produce seroma. These findings suggest that the presence of ADM may be one of the causes of longer displacement of surgical clips by affecting the formation of seroma.

Our study demonstrated that displacement of surgical clips was greater in patients with ADM compared to those without $\mathrm{ADM}$. Thus, using initial planning $\mathrm{CT}$ alone may be inadequate for patients with ADM, resulting in suboptimal local control, more late effects and poorer cosmetic outcome. Although this takes time and involves extra radiation exposure, second simulation CT scan before tumor bed boost allows adaptive planning for displacement of the surgical clips, and therefore should be considered in patients with ADM in the excision cavity.

The current study found that displacement of surgical clips was inversely correlated with the interval between BCS and the start of RT. Weed et al. [23] also reported that the time interval from surgery to first planning CT scan was inversely proportional to the volume change of excision cavity. Petersen et al. [24] noted that change of the excision cavity volume between postoperative $\mathrm{CT}$ scan and planning $\mathrm{CT}$ scan was $2.1 \%$ per day in patients receiving immediate adjuvant RT after BCS and $0.4 \%$ per day in patients receiving postoperative chemotherapy between BCS and RT. These findings suggested that the volume change of the tumor bed is inversely proportional to the time interval between BCS and RT.

Our study had several limitations. Despite the displacement of surgical clips before and during the course of whole breast irradiation, no study addressed the dosimetric effects of such changes or its impact on local control. The displacement of surgical clips can affect the boost dose distribution. A previous study of Sager et al. [25] showed that during conventionally fractionated whole breast irradiation course, boost target volume had a median of $45.97 \%$ reduction, and doses to the heart and ipsilateral lung were significantly reduced with adaptive RT. Alderliesten et al. [26] reported that when the dosimetric effect of seroma absorption was evaluated by comparing three boost RT techniques (simultaneous integrated boost [SIB] RT, sequential boost RT, and SIB adaptive RT), seroma volume had a mean of $62.0 \%$ reduction, and the boost planning target volume receiving at least 95\% of prescribed dose was significantly smaller with SIB adaptive RT compared to both sequential boost RT and SIB. Therefore, evaluation on the dosimetric impact of ADM insertion by comparative assessment between CT 1 and CT 2 is also required in the future.

In conclusion, this study demonstrated the displacement of surgical clips during whole breast irradiation especially in patients with ADM insertion. For patients who had breast volume replacement using ADM, CT simulation at boost planning should be considered.

\section{Conflicts of Interest}

Conflict of interest relevant to this article was not reported.

\section{References}

1. Bartelink H, Horiot JC, Poortmans P, Struikmans H, Van den Bogaert W, Barillot I, et al. Recurrence rates after treatment of breast cancer with standard radiotherapy with or without additional radiation. N Engl J Med. 2001;345:1378-87.

2. Bartelink H, Horiot JC, Poortmans PM, Struikmans H, Van den Bogaert W, Fourquet A, et al. Impact of a higher radiation dose on local control and survival in breast-conserving therapy of early breast cancer: 10-year results of the randomized boost versus no boost EORTC 22881-10882 trial. J Clin Oncol. 2007;25:3259-65.

3. Kirova YM, Fournier-Bidoz N, Servois V, Laki F, Pollet GA, Salmon R, et al. How to boost the breast tumor bed? A multi- 
disciplinary approach in eight steps. Int J Radiat Oncol Biol Phys. 2008;72:494-500.

4. Lee R, Chung E, Lee J, Suh H. Evaluation of electron boost fields based on surgical clips and operative scars in definitive breast irradiation. J Korean Soc Ther Radiol Oncol. 2005;23: 236-42.

5. Goldberg H, Prosnitz RG, Olson JA, Marks LB. Definition of postlumpectomy tumor bed for radiotherapy boost field planning: CT versus surgical clips. Int J Radiat Oncol Biol Phys. 2005;63:209-13.

6. Bedwinek J. Breast conserving surgery and irradiation: the importance of demarcating the excision cavity with surgical clips. Int J Radiat Oncol Biol Phys. 1993;26:675-9.

7. Hunter MA, McFall TA, Hehr KA. Breast-conserving surgery for primary breast cancer: necessity for surgical clips to define the tumor bed for radiation planning. Radiology. 1996;200: 281-2.

8. Harrington KJ, Harrison M, Bayle P, Evans K, Dunn PA, Lambert HE, et al. Surgical clips in planning the electron boost in breast cancer: a qualitative and quantitative evaluation. Int J Radiat Oncol Biol Phys. 1996;34:579-84.

9. Sung S, Lee JH, Lee JH, Kim SH, Kwak YK, Lee SW, et al. Displacement of surgical clips during postoperative radiotherapy in breast cancer patients who received breast-conserving surgery. J Breast Cancer. 2016;19:417-22.

10. Hepel JT, Evans SB, Hiatt JR, Price LL, DiPetrillo T, Wazer DE, et al. Planning the breast boost: comparison of three techniques and evolution of tumor bed during treatment. Int J Radiat Oncol Biol Phys. 2009;74:458-63.

11. Harris EJ, Donovan EM, Yarnold JR, Coles CE, Evans PM; IMPORT Trial Management Group. Characterization of target volume changes during breast radiotherapy using implanted fiducial markers and portal imaging. Int J Radiat Oncol Biol Phys. 2009;73:958-66.

12. Oh KS, Kong FM, Griffith KA, Yanke B, Pierce LJ. Planning the breast tumor bed boost: changes in the excision cavity volume and surgical scar location after breast-conserving surgery and whole-breast irradiation. Int J Radiat Oncol Biol Phys. 2006;66:680-6.

13. Inaji $H$, Yanagisawa T, Komoike $Y$, Motomura K, Koyama $H$. Wide excision as a method of breast-conserving surgery for breast cancer. Nihon Geka Gakkai Zasshi. 2002;103:806-10.

14. Leong C, Boyages J, Jayasinghe UW, Bilous M, Ung O, Chua $\mathrm{B}$, et al. Effect of margins on ipsilateral breast tumor recurrence after breast conservation therapy for lymph node-negative breast carcinoma. Cancer. 2004;100:1823-32.

15. Horiguchi J, Iino Y, Takei H, Maemura M, Yokoe T, Niibe H, et al. Surgical margin and breast recurrence after breast-conserving therapy. Oncol Rep. 1999;6:135-8.

16. Wazer DE, DiPetrillo T, Schmidt-Ullrich R, Weld L, Smith TJ, Marchant DJ, et al. Factors influencing cosmetic outcome and complication risk after conservative surgery and radiotherapy for early-stage breast carcinoma. J Clin Oncol. 1992;10:356-63.

17. Denham JW, Sillar RW, Clarke D. Boost dosage to the excision site following conservative surgery for breast cancer: it's easy to miss! Clin Oncol (R Coll Radiol). 1991;3:257-61.

18. Prendergast B, Indelicato DJ, Grobmyer SR, Saito AI, Lightsey JL, Snead FE, et al. The dynamic tumor bed: volumetric changes in the lumpectomy cavity during breast-conserving therapy. Int J Radiat Oncol Biol Phys. 2009;74:695-701.

19. Chung MJ, Suh YJ, Lee HC, Kang DG, Kim EJ, Kim SH, et al. Tumor bed volumetric changes during breast irradiation for the patients with breast cancer. Radiat Oncol J. 2013;31:228-33.

20. Hernanz F, Regano S, Redondo-Figuero C, Orallo V, Erasun F, Gomez-Fleitas M. Oncoplastic breast-conserving surgery: analysis of quadrantectomy and immediate reconstruction with latissimus dorsi flap. World J Surg. 2007;31:1934-40.

21. Alco G, Igdem S, Okkan S, Dincer M, Sarsenov D, Ilgun AS, et al. Replacement of the tumor bed following oncoplastic breastconserving surgery with immediate latissimus dorsi mini-flap. Mol Clin Oncol. 2016;5:365-71.

22. Jordan SW, Khavanin N, Kim JY. Seroma in prosthetic breast reconstruction. Plast Reconstr Surg. 2016;137:1104-16.

23. Weed DW, Yan D, Martinez AA, Vicini FA, Wilkinson TJ, Wong J. The validity of surgical clips as a radiographic surrogate for the lumpectomy cavity in image-guided accelerated partial breast irradiation. Int J Radiat Oncol Biol Phys. 2004;60: 484-92.

24. Petersen RP, Truong PT, Kader HA, Berthelet E, Lee JC, Hilts $\mathrm{ML}$, et al. Target volume delineation for partial breast radiotherapy planning: clinical characteristics associated with low interobserver concordance. Int J Radiat Oncol Biol Phys. 2007; 69:41-8.

25. Sager O, Dincoglan F, Uysal B, Demiral S, Gamsiz H, Elcim Y, et al. Evaluation of adaptive radiotherapy (ART) by use of replanning the tumor bed boost with repeated computed tomography (CT) simulation after whole breast irradiation (WBI) for breast cancer patients having clinically evident seroma. Jpn J Radiol. 2018;36:401-6.

26. Alderliesten T, den Hollander S, Yang TJ, Elkhuizen PH, van Mourik AM, Hurkmans C, et al. Dosimetric impact of postoperative seroma reduction during radiotherapy after breastconserving surgery. Radiother Oncol. 2011;100:265-70. 